\title{
Physician burnout in Nigeria: a multicentre, cross-sectional study
}

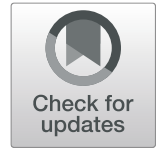

\author{
Arinze D. G. Nwosu ${ }^{1 *} \mathbb{D}$, Edmund N. Ossai ${ }^{2}$, Uwakwe C. Mba ${ }^{3}$, Ifeanyi Anikwe ${ }^{4}$, Richard Ewah ${ }^{5}$, \\ Bernard O. Obande ${ }^{6}$ and Justin U. Achor ${ }^{7}$
}

\begin{abstract}
Background: Healthcare workers are a burnout-prone occupational group and the prevalence is particularly high among physicians. With the prevailing low physician-patient ratio in Nigeria which has worsened with the recent wave of physician emigration, among other socio-economic constraints; a setting for high physician burnout may have been nurtured. Our survey set out to determine the prevalence of burnout among physicians practicing in Nigeria, ascertain the factors that were associated with the development of burnout and evaluate the respondents' perceived impact of physician burnout on patient safety.
\end{abstract}

Methods: We used the Oldenburg burnout inventory as the measurement tool for burnout in the cross-sectional study conducted between November and December, 2019 among physicians in five tertiary health institutions in Nigeria. A 5- point Likert-type scale was used to evaluate the participants rating of their perceived impact of physician burnout on patient safety. Data entry and analysis were done using IBM Statistical package for social sciences software version 25 and the level of statistical significance was determined by a $p$ value $<0.05$.

Results: The response rate was 61\% (535/871), and burnout prevalence was 75.5\% (404/535). Majority of the physicians (74.6\%) perceive that physician burnout could impact patient safety. Physicians' professional grade, age and years in practice, but not specialty, gender or marital status were associated with the exhaustion domain, whereas only the physicians' age was associated with the disengagement domain of burnout. No sociodemographic or work-related characteristics determined overall burnout in our respondents.

Conclusion: Physician burnout in Nigeria is high and pervasive, and this should alert physicians to be wary of their general and mental health status. Public health policy should address this development which has implications for patient safety, physician safety and healthcare system performance.

Keywords: Burnout, Occupation, Physician, Patient safety, Oldenburg burnout inventory

\section{Background}

Burnout is a psychological syndrome that may develop when employees are exposed to a stressful working environment, with high job demands and low resources occurring simultaneously, resulting in exhaustion and disengagement; two related but conceptually distinct domains that constitute the core elements of burnout [1]. The service

\footnotetext{
* Correspondence: adnwosu@yahoo.com

${ }^{1}$ Department of Anaesthesia, National Orthopaedic Hospital, Enugu, Nigeria Full list of author information is available at the end of the article
}

relationships that providers in the human services develop with recipients involve long hours of selfless service with intense level of personal and emotional contact. This pattern of interaction results in significantly higher levels of exhaustion and disengagement among health care workers compared to white collar workers as observed in a burnout evaluation among Dutch workforce [2]. Physicians are among the healthcare workers, but further constrained by statutory regulations and ethical considerations, excessive workload and huge clerical burden. Burnout is more

(c) The Author(s). 2020 Open Access This article is licensed under a Creative Commons Attribution 4.0 International License, which permits use, sharing, adaptation, distribution and reproduction in any medium or format, as long as you give appropriate credit to the original author(s) and the source, provide a link to the Creative Commons licence, and indicate if changes were made. The images or other third party material in this article are included in the article's Creative Commons licence, unless indicated otherwise in a credit line to the material. If material is not included in the article's Creative Commons licence and your intended use is not permitted by statutory regulation or exceeds the permitted use, you will need to obtain permission directly from the copyright holder. To view a copy of this licence, visit http://creativecommons.org/licenses/by/4.0/ The Creative Commons Public Domain Dedication waiver (http://creativecommons.org/publicdomain/zero/1.0/) applies to the data made available in this article, unless otherwise stated in a credit line to the data. 
common among physicians than other workers in the healthcare sector [3] and general population [4]. There is strong evidence that burnout is associated with poorer self-rated health and depression among healthcare workers [5]. Therefore physician burnout has crucial implication for their performance as well as the safety of their patient and self.

\section{Physician burnout and patient safety}

There has been consistency in the association between burnout syndrome in healthcare workers and suboptimal and unsafe care of patients [6]. Major medical errors in surgical practice have been reported to be strongly related to the surgeon's degree of burnout [7]. Selfreported suboptimal care of patients by physicians has also been attributed to burnout [8,9]. Further evidence from a systematic review also supports that physician burnout is associated with an increased risk of patient safety incidents, poorer quality of care due to low professionalism, and reduced patient satisfaction [10].

\section{The Maslach burnout inventory (MBI) and Oldenburg burnout inventory (OLBI)}

By far the MBI has been the predominant instrument for measuring burnout $[11,12]$ and has historically been regarded as the gold standard. According to Maslach, burnout consists of three dimensions: emotional exhaustion, depersonalization (felt distance from others), and diminished personal accomplishment. From this original version the MBI-Human services survey (MBI-HSS) [13] has evolved the MBI-General survey (MBI-GS) [14] based on the domains of exhaustion, cynicism and professional efficacy. However, whereas there is wide consensus on the multidimensional construct of burnout as against a uni-dimensional model, correlation between the personal accomplishment /professional efficacy dimension and the two others (Exhaustion and disengagement/ depersonalization/ cynicism) is low and this controversial component of the MBI has been questioned and challenged by several researchers [2, 15-18].

The OLBI is a validated instrument for measuring burnout $[2,19,20]$ and there is growing evidence in support of its use $[1,19]$. Convergence validity between the OLBI and MBI-GS has since been established [21]. The OLBI measures burnout with two dimensions: exhaustion and disengagement. In contrast to the MBI which includes only the emotional component of exhaustion, the OLBI makes provision for the physical and cognitive components of exhaustion. Furthermore, in the eight items of each domain of OLBI four items are positively worded while the four others are negatively worded, making for psychometric balancing.

Compounding the low physician-patient ratio and meager infrastructure in Nigeria, the country has witnessed massive emigration of her physician workforce overseas in recent years with the resultant creation of a healthcare system that could arguably drive physician burnout. Consequently, despite sparse literature on this occupational syndrome in Nigeria physician burnout may be pervading the practice space, albeit silently. We sought to determine the level of burnout among physicians in Nigeria, and the individual characteristics that are predictive of experiencing burnout.

\section{Methods}

\section{Study design}

A cross- sectional survey was conducted on physicians in five tertiary health institutions in Nigeria between November and December, 2019 using a pre-tested semistructured questionnaire.

\section{Ethical approval}

The Institutional review board of National Orthopedic Hospital, Enugu gave approval for the study and verbal informed consent to participate in the study was obtained from all the participating physicians.

\section{Sample population and participants}

All physicians in all the departments of the enlisted health institutions were eligible for participation in the study. A total population sample of all the physicians in the five tertiary health institutions, located in three states of Nigeria; four in the southern part and one in the northern part of the country was carried out. Owing to their nature as training institutions and other inherent logistic weaknesses it was not possible to obtain the exact number of physicians in any of the centres as entry and exit into the various programs were constantly in a state of flux. In effect, the total number of physicians credited to each institution was the adjudged best estimate from the Association of Resident Doctors (ARD) and Medical and Dental Consultants Association of Nigeria (MDCAN) membership record; these being two broad groups to which all the physicians in the institutions belong. The study questionnaires were in print (paper) format and to minimize response bias they were anonymous and self-administered by the respondents.

\section{Survey administration}

The questionnaire titled "A SOCIAL SURVEY OF FEEL INGS AND ATTITUDES DURING WORK” comprised of three sections; (i) biodata section of the respondents (ii) a Likert-type scale of respondents rating of the impact of physician burnout on patient safety and (iii) the English version of the 16-item OLBI which is not so labeled. This generic labeling was adopted in an effort to fend off response bias to the tool, which might result if "burnout" were to be expressly mentioned. Each questionnaire is introduced with a definition of burnout thus; 
Burnout is a psychological syndrome that may result from exposure to a stressful working environment; with high job demands and low resources occurring simultaneously, resulting in exhaustion (general feeling of overtasking from work) and disengagement (distancing oneself from ones work and negative attitude towards ones work). This is to enable the respondents give informed opinion of how they individually relate burnout to patient safety in the accompanying Likert -type tool. The tool for rating of influence of physician burnout on patient safety is framed thus "Rate your perception of physician burnout as being relevant to patient safety" with the following options; strongly disagree, disagree, undecided, agree, strongly agree.

\section{Survey tool -the OLBI instrument}

Oldenburg burnout inventory is a 16-item survey with positively and negatively framed items which measure burnout with two dimensions: exhaustion (physical, cognitive, and affective aspects) and disengagement (negative attitudes toward work objects, work content, or work in general) [2]. In the 16-item version of the instrument used for this study each of these two dimensions is represented by 8 items; with four in each dimension being positively worded and four negatively worded and arranged in a mixed pattern for psychometric balancing. Items $2,4,5,8,10,12,14$ and 16 explore exhaustion, while $1,3,6,7,9,11,13$ and 15 explore disengagement. Each item has four Likert-type response options which are scored; strongly agree-1, agree-2, disagree-3, strongly disagree-4. Reverse scoring is applied to the items marked with an ' $R$ ' in the instrument such that strongly agree is scored-4 and strongly disagree-1. In all instances higher scores indicate higher exhaustion and disengagement.

\section{Data collection}

The respondents were introduced to the survey during weekly departmental clinical meetings and outpatient clinic sessions. Repeat rounds of visits were made over three weeks by the research assistants to enable the recovery of questionnaires from those who could not complete theirs on the day of the initial distribution and to extend the distribution to those who were not reached previously.

\section{Outcome assessment}

The main outcome assessed was burnout as measured by exhaustion and disengagement domain scores of the OLBI tool. Additional outcome measure assessed in the study was the respondents rating of physician burnout as relevant to patient safety; using the 5-item Likert-type template provided in the first section of the questionnaire with options graded as strongly disagree, disagree, undecided, agree, and strongly agree. For the purpose of analysis, the responses in the latter were dichotomized such that the responses of 'agree' and 'strongly agree' were regarded as YES while the responses of 'strongly disagree', 'disagree' and 'undecided' were regarded as NO with respect to the respondents perception of physician burnout as relevant issue to patient safety.

\section{Data analysis}

Data entry and analysis were done using the statistical package for social sciences (SPSS) software version 25 (IBM, Armonk, New York, USA). Continuous variables were summarized using mean and standard deviation while categorical variables were summarized using proportions. For inferential statistics the Student t test was used to compare the difference in mean of two samples, Chi square test was used to compare difference in proportions and ANOVA was used to compare the difference in mean of more than two samples. The level of statistical significance was determined by a $p$ value of $<0.05$.

To identify the burnout groups, mean scores $\geq 2.25$ on the exhaustion domain were considered as having high exhaustion, while those who scored less than 2.25 were regarded as having low Exhaustion. For the disengagement domain mean scores $\geq 2.1$ were considered as high while those who scored less than 2.1 were regarded as having low Disengagement. These cut-off scores were adapted from a previous study on burnout among Swedish healthcare workers conducted with the OLBI [5]. The mean score for each domain is obtained by dividing the total scores for the items in the domain by the number of items in the domain; which is eight (8) in each case. The following categories emerged from the respondents;

\section{Burnout group: high exhaustion and high \\ disengagement \\ Exhausted group: high exhaustion and low \\ disengagement \\ Disengaged group: high disengagement and low exhaustion \\ Non-burnout group: low disengagement and low exhaustion}

In order to contend with the unwieldy number of specialties and subspecialties while considering the specialty of the physicians we applied the West African Postgraduate Medical College board classification such that; surgical specialties referred to general surgery, anesthesia, neurosurgery, cardiothoracic surgery, ophthalmology, otorhinolaryngology, pediatric surgery, maxillofacial surgery, orthopedic surgery, plastic surgery, pathology, radiology, obstetrics and gynecology while medical specialties referred to internal medicine, community medicine, psychiatry, family medicine and pediatrics. Medical officers and interns are nonspecialists and as such were grouped as 'Others'. 


\section{Results}

\section{Response rate}

In National Orthopedic Hospital (NOHE), Enugu, out of 73 physicians 65 questionnaires were duly completed; in Federal Teaching Hospital, Abakaliki (FETHA) out of 430 physicians 186 questionnaires were completed; in Enugu State University Teaching Hospital (ESUTH) with 220 physicians 167 questionnaires were completed; in Federal Medical Centre (FMC), Makurdi with 124 physicians 97 questionnaires were completed, while in Federal Neuropsychiatric Hospital (FNPH), Enugu out of 24 physicians 20 completed questionnaires were returned: implying a response rate of $89,43,76,78$ and $83 \%$ respectively. In sum 535 duly completed questionnaires were returned out of a total physician population of 871 , yielding a response rate of $61 \%$.

\section{Participants perception of burnout impact on patient safety}

In responding to their perception of physician burnout as relevant to patient safety; 74.6\% (399/535) perceive physician burnout as relevant to patient safety, while 25.4\% (136/535) disagreed.

Table 1 shows that males made up $73.8 \%$ of the respondents, married physicians $72.1 \%$, and resident doctors $59.4 \%$. The male and female physicians had the same mean exhaustion score, $2.7 \pm 0.4$ and mean disengagement score of $2.4 \pm 0.4$.

Table 1 Socio-demographic characteristics of respondents

\begin{tabular}{|c|c|c|c|}
\hline Variable & Frequency $(n=535)$ & Exhaustion Mean( \pm SD) & Disengagement Mean \pm SD \\
\hline \multicolumn{4}{|c|}{ Age of respondents in groups } \\
\hline$<35$ years & $195(36.4)$ & $2.7 \pm 0.4$ & $2.4 \pm 0.4$ \\
\hline $35-39$ years & $158(29.5)$ & $2.7 \pm 0.4$ & $2.5 \pm 0.4$ \\
\hline$\geq 40$ years & $182(34.0)$ & $2.6 \pm 0.4$ & $2.4 \pm 0.4$ \\
\hline \multicolumn{4}{|l|}{ Gender } \\
\hline Male & $395(73.8)$ & $2.7 \pm 0.4$ & $2.4 \pm 0.4$ \\
\hline Female & $140(26.2)$ & $2.7 \pm 0.4$ & $2.4 \pm 0.4$ \\
\hline \multicolumn{4}{|l|}{ Marital status } \\
\hline Married & $386(72.1)$ & $2.7 \pm 0.4$ & $2.4 \pm 0.4$ \\
\hline Single & $149(27.9)$ & $2.7 \pm 0.4$ & $2.4 \pm 0.4$ \\
\hline \multicolumn{4}{|c|}{ Number of years in practice } \\
\hline$<5$ years & $148(27.7)$ & $2.8 \pm 0.4$ & $2.4 \pm 0.4$ \\
\hline $5-9$ years & $134(25.0)$ & $2.7 \pm 0.4$ & $2.4 \pm 0.4$ \\
\hline 10-14 years & $164(30.7)$ & $2.6 \pm 0.5$ & $2.4 \pm 0.4$ \\
\hline$\geq 15$ years & 89 (16.6) & $2.5 \pm 0.4$ & $2.3 \pm 0.4$ \\
\hline \multicolumn{4}{|c|}{ Professional grade of physicians } \\
\hline Medical consultant & 79 (14.8) & $2.5 \pm 0.4$ & $2.3 \pm 0.4$ \\
\hline Medical officer & $22(4.1)$ & $2.7 \pm 0.5$ & $2.4 \pm 0.5$ \\
\hline Resident doctor & $318(59.4)$ & $2.7 \pm 0.4$ & $2.4 \pm 0.4$ \\
\hline Medical intern & $116(21.7)$ & $2.7 \pm 0.4$ & $2.4 \pm 0.4$ \\
\hline \multicolumn{4}{|l|}{ Institution } \\
\hline NOHE, Enugu. & $65(12.1)$ & $2.6 \pm 0.4$ & $2.4 \pm 0.4$ \\
\hline FETHA, Abakaliki. & $186(34.8)$ & $2.6 \pm 0.4$ & $2.4 \pm 0.4$ \\
\hline ESUTH, Enugu. & $167(31.2)$ & $2.7 \pm 0.4$ & $2.4 \pm 0.4$ \\
\hline FMC, Makurdi. & $97(18.1)$ & $2.7 \pm 0.4$ & $2.4 \pm 0.4$ \\
\hline FNPH, Enugu. & $20(3.7)$ & $2.6 \pm 0.5$ & $2.3 \pm 0.4$ \\
\hline \multicolumn{4}{|c|}{ Medical specialty of respondents } \\
\hline Surgical specialties & $261(48.8)$ & $2.7 \pm 0.4$ & $2.4 \pm 0.4$ \\
\hline Medical Specialties & $136(25.4)$ & $2.6 \pm 0.4$ & $2.4 \pm 0.4$ \\
\hline Others* & $138(25.8)$ & $2.7 \pm 0.4$ & $12.4 \pm 0.4$ \\
\hline
\end{tabular}

*No specific specialty 
Table 2 Association between exhaustion scores and respondents characteristics

\begin{tabular}{|c|c|c|c|c|}
\hline Variable & $(n=535)$ & Exhaustion Mean $( \pm S D)$ & $\mathrm{F}$ & $p$ value \\
\hline \multicolumn{5}{|c|}{ Professional grade of physicians } \\
\hline Medical consultant & 79 & $2.5 \pm 0.4$ & 6.793 & $<0.001$ \\
\hline Medical officer & 22 & $2.7 \pm 0.5$ & & \\
\hline Resident doctor & 318 & $2.7 \pm 0.4$ & & \\
\hline Medical intern & 116 & $2.7 \pm 0.4$ & & \\
\hline \multicolumn{5}{|c|}{ Age group of physicians } \\
\hline$<35$ years & 195 & $2.7 \pm 0.4$ & 10.734 & $<0.001$ \\
\hline $35-39$ years & 158 & $2.7 \pm 0.4$ & & \\
\hline$\geq 40$ years & 182 & $2.6 \pm 0.4$ & & \\
\hline \multicolumn{5}{|l|}{ Years in practice } \\
\hline$<5$ years & 148 & $2.8 \pm 0.4$ & 9.317 & $<0.001$ \\
\hline $5-9$ years & 134 & $2.7 \pm 0.4$ & & \\
\hline $10-14$ years & 164 & $2.6 \pm 0.5$ & & \\
\hline$\geq 15$ years & 89 & $2.5 \pm 0.4$ & & \\
\hline \multicolumn{5}{|l|}{ Specialties } \\
\hline Surgical specialties & 261 & $2.7 \pm 0.4$ & 1.811 & 0.164 \\
\hline Medical specialties & 136 & $2.6 \pm 0.4$ & & \\
\hline Others* & 138 & $2.7 \pm 0.4$ & & \\
\hline \multicolumn{5}{|l|}{ Gender } \\
\hline Male & 395 & $2.7 \pm 0.4$ & $1.616^{* *}$ & 0.107 \\
\hline Female & 140 & $2.7 \pm 0.4$ & & \\
\hline \multicolumn{5}{|l|}{ Marital status } \\
\hline Married & 386 & $2.7 \pm 0.4$ & $1.792^{* *}$ & 0.074 \\
\hline Single & 149 & $2.7 \pm 0.4$ & & \\
\hline
\end{tabular}

${ }^{*}$ No specific specialty ${ }^{* *}$ Student $\mathrm{t}$ test

Table 2, shows that the difference in the mean of exhaustion domain scores is statistically significant with respect to the physicians' professional grade, age, and years in practice.

From Table 3, we observed that the medical officers had the highest mean disengagement score, $2.4 \pm 0.5$ while the medical consultants had the least, $2.3 \pm 0.4$ but the difference in mean was not statistically significant, $(\mathrm{F}=2.091, p=1.0)$. The respondents in the age group, 35-39 years had the highest mean disengagement score, $2.5 \pm 0.4$ and the difference in mean was statistically significant, $(\mathrm{F}=3.183, \quad p=$ 0.042).

The highest proportion of respondents, $75.5 \%$ were in the burnout group (Table 4.).

There was no association between burnout and hospital characteristics of the respondents $\left(\mathrm{x}^{2}=1.373, p=\right.$ 0.849 ) and comparable proportions of male (76.7\%) and females respondents $(75.0 \%)$ were in the physician burnout group, $\left(x^{2}=0.027, p=0.869\right)$.

\section{Discussion}

We found that $75.5 \%$ of the physicians surveyed were burnt-out, but no individual or institutional predictors of overall burnout were identified. A majority of the physicians $(74.6 \%)$ perceive that physician burnout could impact patient safety.

While there is paucity of studies examining physicians' perception of burnout's impact on patient safety, a majority of burnout-prone healthcare workers surveyed in a tertiary health institution in Rwanda aver to suboptimal patient care, medical errors and poor outcome which they attributed to burnout [22].

The overall response rate recorded in the study $(61 \%)$ was comparable to that obtained in two previous studies on physician burnout in Nigeria [23, 24]. Nevertheless the response rate of $43 \%$ in one of the institutions (FETHA, Abakaliki) was disproportionately low compared to the other institutions. The institution is a relatively new one with a significant number of physicians being primarily employed elsewhere. High response rate and the mode of 
Table 3 Association between disengagement scores and respondents characteristics

\begin{tabular}{|c|c|c|c|c|}
\hline Variable & $(n=535)$ & Disengagement Mean ( \pm SD) & $\mathrm{F}$ & $p$ value \\
\hline \multicolumn{5}{|c|}{ Professional grade of physicians } \\
\hline Medical consultant & 79 & $2.3 \pm 0.4$ & 2.091 & 1.0 \\
\hline Medical officer & 22 & $2.4 \pm 0.5$ & & \\
\hline Resident doctor & 318 & $2.4 \pm 0.4$ & & \\
\hline Medical intern & 116 & $2.4 \pm 0.4$ & & \\
\hline \multicolumn{5}{|c|}{ Age groups of physicians } \\
\hline$<35$ years & 195 & $2.4 \pm 0.4$ & 3.183 & 0.042 \\
\hline $35-39$ years & 158 & $2.5 \pm 0.4$ & & \\
\hline$\geq 40$ years & 182 & $2.4 \pm 0.4$ & & \\
\hline \multicolumn{5}{|l|}{ Years in practice } \\
\hline$<5$ years & 148 & $2.4 \pm 0.4$ & 1.638 & 0.180 \\
\hline $5-9$ years & 134 & $2.4 \pm 0.4$ & & \\
\hline $10-14$ years & 164 & $2.4 \pm 0.4$ & & \\
\hline$\geq 15$ years & 89 & $2.3 \pm 0.4$ & & \\
\hline \multicolumn{5}{|l|}{ Specialties } \\
\hline Surgical specialties & 261 & $2.4 \pm 0.4$ & 0.785 & 0.457 \\
\hline Medical specialties & 136 & $2.4 \pm 0.4$ & & \\
\hline Others* & 138 & $2.4 \pm 0.4$ & & \\
\hline \multicolumn{5}{|l|}{ Gender } \\
\hline Male & 395 & $2.4 \pm 0.4$ & $0.025^{* *}$ & 0.980 \\
\hline Female & 140 & $2.4 \pm 0.4$ & & \\
\hline \multicolumn{5}{|l|}{ Marital status } \\
\hline Married & 386 & $2.4 \pm 0.4$ & $0.933^{* *}$ & 0.351 \\
\hline Single & 149 & $2.4 \pm 0.4$ & & \\
\hline
\end{tabular}

*No specific specialty **Student $t$ test

questionnaire administration (paper, self-administered) used in this study have been found to minimize bias and positively impact on the quality of data generated and the validity of the results of a research [25].

The high prevalence of burnout found in this study (75.5\%) is supported by the report of a meta-analysis of physician burnout across global regions (which lamented paucity of research on physician burnout in Africa) that found physician burnout to be positively associated with workload, constraining organizational structure, violence and low safety standards [26]; all of which characterize the current work environment of the physician practicing in

Table 4 Burnout category of the physicians

\begin{tabular}{lll}
\hline Variable & Frequency $(\boldsymbol{n}=\mathbf{5 3 5})$ & Percent (\%) \\
\hline Burnout grouping & & \\
Non Burnout group & 34 & 6.4 \\
Disengaged group & 27 & 5.0 \\
Exhausted group & 70 & 13.1 \\
Burnout group & 404 & 75.5 \\
\hline
\end{tabular}

Nigeria. There had been few published works on physician burnout in Nigeria. One of them, a small survey of orthopedic surgeons had reported a burnout prevalence of $51.7 \%$ $(15 / 29)$ [27]. Two other Nigerian studies are equally very limited in scope; being restricted to primary care physicians in a city [23], and resident doctors in a single institution [24]. All three studies were carried out between 2010 and 2015; a period predating the current wave of Nigerian physician emigration to Europe and the Middle East. Among the few studies on physician burnout conducted elsewhere in Africa, prevalence of 81 and $76 \%$ respectively were reported among physicians in South African rural district hospitals and urban hospitals respectively $[28,29]$. In a 2017 study of all physicians working in all the public hospitals (primary, secondary and tertiary) in Southern Ethiopia, burnout was pervasive; with $65.2 \%$ of physicians scoring high on emotional exhaustion, $85.1 \%$ showed high degree of depersonalization and $91 \%$ of them experienced low level of personal accomplishment [30]. A systematic review of burnout among physicians in the UK conducted in 2013 rated high emotional exhaustion scores in the range of 31 to $54.3 \%$; high depersonalization scores ranged from 17.4 to 
$44.5 \%$ and for low personal accomplishment the range was 6-39.6\% [31].

Our study revealed a strong association between the exhaustion domain of burnout and professional grade, age and years in practice of the physician (see Table 2), while the only association found in respect of the disengagement domain was with the age group of the physicians (see Table 3). These associations were however only applicable as far as the independent domains of burnout are considered, but none of these or other socio-demographic and work-related characteristics were found to predict overall burnout in our respondents (see Table 5). This inability to locate any socio-demographic predictor of burnout in the respondents may suggest

Table 5 Determinants of burnout among the physician

\begin{tabular}{|c|c|c|c|c|}
\hline \multirow[t]{2}{*}{ Variable } & \multicolumn{2}{|c|}{ Physician Burnout $(n=535)$} & \multirow[t]{2}{*}{$x^{2}$} & \multirow{2}{*}{$\begin{array}{l}p \\
\text { value }\end{array}$} \\
\hline & Yes $N(\%)$ & No $N(\%)$ & & \\
\hline \multicolumn{5}{|c|}{ Age of respondents in groups } \\
\hline$<38$ years & $227(77.2)$ & $67(22.8)$ & 1.016 & 0.313 \\
\hline$\geq 38$ years & $177(73.4)$ & $64(26.6)$ & & \\
\hline \multicolumn{5}{|l|}{ Gender } \\
\hline Male & $299(76.7)$ & $96(24.3)$ & 0.027 & 0.869 \\
\hline Female & $105(75.0)$ & $35(25.0)$ & & \\
\hline \multicolumn{5}{|l|}{ Marital status } \\
\hline Married & $288(74.6)$ & $98(25.4)$ & 0.611 & 0.435 \\
\hline Single & $116(77.9)$ & $33(22.1)$ & & \\
\hline \multicolumn{5}{|c|}{ Number of years in practice } \\
\hline$<10$ years & $221(78.4)$ & $61(21.6)$ & 2.628 & 0.105 \\
\hline$\geq 10$ years & $183(72.3)$ & $70(27.7)$ & & \\
\hline \multicolumn{5}{|c|}{ Professional grade of physicians } \\
\hline Medical consultant & $54(68.4)$ & $25(31.6)$ & 3.453 & 0.327 \\
\hline Medical officer & $16(72.7)$ & $6(27.3)$ & & \\
\hline Resident doctor & $248(78.0)$ & $30(25.9)$ & & \\
\hline Medical intern & $86(74.1)$ & $30(25.9)$ & & \\
\hline \multicolumn{5}{|l|}{ Institution } \\
\hline NOHE, Enugu. & $47(72.3)$ & $18(27.7)$ & 1.373 & 0.849 \\
\hline FETHA, Abakaliki. & $137(73.7)$ & $49(26.3)$ & & \\
\hline ESUTH, Enugu. & $130(77.8)$ & $37(22.7)$ & & \\
\hline FMC, Makurdi & $75(77.3)$ & $22(22.7)$ & & \\
\hline FNPH, Enugu. & $15(75.0)$ & $5(25.0)$ & & \\
\hline \multicolumn{5}{|c|}{ Perception of burnout as relevant to patient safety } \\
\hline Yes & $305(76.4)$ & $94(23.6)$ & 0.730 & 0.393 \\
\hline No & $99(72.8)$ & $37(27.2)$ & & \\
\hline \multicolumn{5}{|l|}{ Specialties } \\
\hline Surgical specialties & $201(77.0)$ & $60(23.0)$ & 0.623 & 0.732 \\
\hline Medical specialties & $101(74.3)$ & $35(25.7)$ & & \\
\hline Others* & $102(73.9)$ & $36(26.1)$ & & \\
\hline
\end{tabular}

that factors external to the individual physicians - system factors, are responsible. This postulation is supported by the findings of a meta-analysis that evaluated the effectiveness of different types of interventions to reduce burnout in physicians [32]. Thus with the greater improvement credited to organization-directed interventions compared with physician-directed interventions in the meta-analysis it concluded that organizational factors, more than individual factors, drive physician burnout. The finding of similar burnout indices in the different health institutions surveyed may thus reflect the pervasive and universal nature of the burnoutpromoting practice environment in the country. A UK study to assess the prevalence of psychological morbidity across different surgical specialties revealed that burnout prevalence did not differ significantly between specialty, professional grade, age, or gender of the surgeon, but that the number of years in the specialty independently predicted scores in the exhaustion domain [33]. Our study did not find any association between physician's specialty and burnout. This may have derived from the fact that the groups as we composed are a cocktail of specialties with disparate and paradoxical attributes in training and practice experience. Furthermore physician interns are a large group with ubiquitous representation in the different specialties in the course of their rotations, as such would not be justifiably allocated to either surgical or medical specialty owing to their mixed exposure and experience. A survey of residents and interns in dermatology, general surgery, internal medicine, family medicine, neurology, obstetrics/gynecology, ophthalmology, and psychiatry departments in a US tertiary health institution reported burnout rates ranging from $75 \%$ in obstetrics/ gynecology to $27 \%$ in family medicine [34]. Another USbased study by Shanafelt et al., [4] reported the highest burnout rates among emergency medicine physicians with lowest rates in preventive medicine and dermatology, but this specialty trend showed significant variation in a subsequent national survey [12]. Meanwhile elsewhere a multicentre survey in Italy found that psychiatrists had higher levels of burnout than other physicians [35].

One major challenge with the prevalence of burnout quoted by many researchers reporting their work with other burnout instruments such as the MBI has been the highly variable criteria that qualify burnout. It is commonplace to find low prevalence with studies in which the criteria is the simultaneous occurrence of high burnout in all the three subscales of exhaustion, depersonalization and low personal accomplishment; such as 4.2\% [36], 8.5\% [37] and $11.7 \%$ [38]. In a study of burnout amongst physicians working in primary care in Saudi Arabia, out of 144 respondents; 48 (33.3\%) scored high burnout in only one subscale, 57 (39.6\%) scored high burnout in two subscales while only $4(2.78 \%)$ scored high burnout in all three subscales. They 
defined high burnout as concurrent high scores in emotional exhaustion $(\geq 27)$, high scores in depersonalization $(\geq 10)$ and low scores in personal accomplishment $(\leq 33)$ and based on this criterion burnout prevalence was reported as $2.78 \%$ [39]. Had they used the criterion that recognizes burnout as concurrent occurrence of high burnout scores in two subscales, the same study may have posted a burnout prevalence of $39.6 \%$ instead of $2.78 \%$. This wide variability in the defining criteria applied by different researchers has elicited concern in a systematic review which revealed five different criteria applied by different researchers, and the attendant implication to burnout prevalence reports [40]. Consequently with the variation in burnout estimation criteria by different researchers it was difficult to make direct comparison between the results of our study and other studies.

The high prevalence of burnout in this study as measured by the OLBI is comparable to other reports from Africa where an alternative tool (MBI) was used. It is supported by the findings of earlier research on correlates of physician burnout across global regions [26] and the twin problem of physician exodus and the prevailing environment of healthcare in Nigeria. The current wave of physician exodus in Nigeria also supports our burnout prevalence as several researchers have reported a remarkable association between burnout among physicians and the intention to emigrate [41, 42].

Against the background of very high burnout among physicians in Nigeria there is justification for further studies to determine its impact on the physicians' health and wellbeing. Longitudinal studies on Nigerian physician emigrants would be necessary to validate the role of system and environmental factors in the high burnout observed at home. Furthermore, implementation of structured system interventions and evaluation of their effect on mitigating burnout among Nigerian physicians are essential, and could represent a robust effort at controlling burnout.

\section{Limitations}

As indicated earlier in the methodology section we were unable to obtain the accurate data on the number of eligible physicians in the respective training institutions. Furthermore, despite the multi-centre and multispecialty design of this study the institutions surveyed are government-owned tertiary health institutions which are located in urban areas. Though these facilities also provide primary and secondary care the findings may not necessarily reflect the scenario in private institutions or health facilities located in the rural areas. This consideration may not be ignored despite the finding of similar trends in a comparative study of physician burnout in South African rural and urban hospitals [28, 29]. Response bias is a known shortcoming of convenient sampling technique which we applied in this study and this could have had some influence on the findings.

\section{Conclusion}

Physician burnout in Nigeria is high and pervasive, and this should alert physicians to be wary of their general and mental health status. Public health policy should address this development which has implications for patient safety, physician safety and healthcare system performance; as the goal of safe and efficient care would remain a mirage with a very unhealthy population of physicians.

\begin{abstract}
Abbreviations
ANOVA: Analysis of variance; ARD: Association of resident doctors; ESUTH: Enugu State University Teaching Hospital; FETHA: Federal Teaching Hospital, Abakaliki; FMC: Federal Medical Centre; FNPH: Federal Neuropsychiatric Hospital; GP: General practitioners; MBI: Maslach burnout inventory; (MBI-GS): MBI-General survey; (MBI-HSS): MBI-Human services survey; MDCAN: Medical and Dental consultants association of Nigeria; NHS: National Health Service; NOHE: National Orthopedic Hospital, Enugu; OLBI: Oldenburg burnout inventory; SPSS: Statistical package for social sciences; UK: United Kingdom
\end{abstract}

\section{Acknowledgements}

We appreciate the invaluable support from Professor Evangelia Demerouti who provided the English translation of each item of the OLBI which we applied in this study alongside the German language version.

\section{Authors' contributions}

AN conceptualized and designed the study, EO analyzed and interpreted the survey data, UM, IA, RE, BO and JA performed the data collection and contributed to the intellectual content. All authors read, revised and approved the final manuscript for submission.

\section{Funding}

Nil.

\section{Availability of data and materials}

The datasets used and analyzed during the current study are available from the corresponding author on reasonable request.

\section{Ethics approval and consent to participate}

The Institutional review board of National Orthopedic Hospital, Enugu gave approval for the study. In the research proposal presented to the Institutional review board for consideration we clearly indicated our method of informed consent to be verbal and the board in her wisdom approved same. Verbal informed consent to participate in the study was obtained from all the participating physicians with assurance of confidentiality of the data.

Consent for publication

Not applicable.

\section{Competing interests}

The authors declare that they have no competing interests.

\section{Author details}

'Department of Anaesthesia, National Orthopaedic Hospital, Enugu, Nigeria. ${ }^{2}$ Department of Community Medicine, College of Health Sciences, Ebonyi State University, Abakaliki, Nigeria. ${ }^{3}$ Department of Plastic Surgery, College Of Medicine, ESUTH, Enugu, Nigeria. ${ }^{4}$ Department of Orthopaedic Surgery, National Orthopaedic Hospital, Enugu, Nigeria. ${ }^{5}$ Department of Anaesthesia, FETHA, Abakaliki, Nigeria. ${ }^{6}$ Department of Orthopaedic Surgery, Federal Medical Centre, Makurdi, Nigeria. ${ }^{7}$ Department of Psychiatry, Federal Neuropsychiatric Hospital, Enugu, Nigeria.

Received: 10 January 2020 Accepted: 2 September 2020

Published online: 14 September 2020

\section{References}

1. Demerouti E, Bakker AB, Nachreiner F, Schaufeli WB. The job demandsresources model of burnout. J Appl Psychol. 2001;86(3):499-512. 
2. Demerouti $E$, Bakker $A B$. The Oldenburg burnout inventory: a good alternative to measure burnout and engagement. In J. Halbesleben (Ed.) Stress and burnout in health care. Hauppauge, NY: Nova Science Publishers; 2008. p. 65-78.

3. Reith TP. Burnout in United States healthcare professionals: a narrative review. Cureus. 2018;10(12):e3681.

4. Shanafelt TD, Boone S, Tan L, Dyrbye LN, Sotile W, Satele D, et al. Burnout and satisfaction with work-life balance among US physicians relative to the general US population. Arch Intern Med. 2012;172(18):1377-85.

5. Peterson U, Demerouti E, Bergström G, Samuelsson M, Asberg M, Nygren A. Burnout and physical and mental health among Swedish healthcare workers. J Adv Nurs. 2008;62(1):84-95.

6. Kim MH, Mazenga AC, Simon K, Yu X, Ahmed S, Nyasulu P, et al. Burnout and self-reported suboptimal patient care amongst health care workers providing HIV care in Malawi. PLoS One. 2018;13(2):e0192983.

7. Shanafelt TD, Balch CM, Bechamps G, Russell T, Dyrbye L, Satele D, et al. Burnout and medical errors among American surgeons. Ann Surg. 2010; 251(6):995-1000.

8. Shanafelt TD, Bradley KA, Wipf JE, Back AL. Burnout and self-reported patient care in an internal medicine residency program. Ann Intern Med. 2002;136(5):358-67.

9. Lu DW, Dresden S, McCloskey C, Branzetti J, Gisondi MA. Impact of burnout on self-reported patient care among emergency physicians. West J Emerg Med. 2015;16(7):996-1001.

10. Panagioti M, Geraghty K, Johnson J, Zhou A, Panagopoulou E, ChewGraham C, et al. Association between physician burnout and patient safety, professionalism, and patient satisfaction: a systematic review and metaanalysis. JAMA Intern Med. 2018;178(10):1317-30.

11. Dubale BW, Friedman LE, Chemali Z, Denninger JW, Mehta DH, Alem A, et al. Systematic review of burnout among healthcare providers in subSaharan Africa. BMC Public Health. 2019;19:1247.

12. Shanafelt TD, West CP, Sinsky C, Trockel M, Tutty M, Satele DV, et al. Changes in burnout and satisfaction with work-life integration in physicians and the general US working population between 2011 and 2017. Mayo Clin Proc. 2019;94(9):1681-94.

13. Maslach C, Jackson SE. The measurement of experienced burnout. J Organ Behav. 1981;2:99-113.

14. Schaufeli WB, Leiter MP, Maslach C, Jackson SE. The Maslach burnout inventory-general survey. In C. Maslach, S.E. Jackson, \& M.P. Leiter (Eds.), Maslach burnout inventory. Palo Alto, CA: Consulting Psychologists Press; 1996.

15. Lee RL, Ashforth BE. A meta-analytic examination of the correlates of the three dimensions of job burnout. J Appl Psychol. 1996;81(2):123-33.

16. Cordes CL, Dougherty TW. A review and an integration of research on job burnout. Acad Manag Rev. 1993;18(4):621-56.

17. Qiao H, Schaufeli WB. The convergent validity of four burnout measures in a Chinese sample: a confirmatory factor-analytic approach. Appl Psychol. 2011;60(1):87-111.

18. Taris TW, Le Blanc PM, Schaufeli WB, Schreurs PJG. Are there causal relationships between the dimensions of the Maslach burnout inventory? A review and two longitudinal tests. Work Stress. 2005;19(3):238-55.

19. Halbesleben JRB, Demerouti $E$. The construct validity of an alternative measure of burnout: investigating the English translation of the Oldenburg burnout inventory. Work Stress. 2005;19(3):208-20.

20. Khan A, Yusoff RBM. Psychometric testing of Oldenburg burnout inventory among academic staff in Pakistan. IRMM. 2016;6(4):683-7.

21. Demerouti $E$, Bakker AB, Vardakou I, Kantas A. The convergent validity of two burnout instruments: a multitrait-multimethod analysis. Eur J Psychol Assess. 2003;19(1):12-23.

22. Cishahayo EU, Tuyisenge MJ, Mwiseneza MJ, Sego R, Bhengu BR. Perceived effects of burnout on patients and its management among nurses in the intensive care unit and emergency Department of a Rwandan University Teaching Hospital. Rwanda J Med Health Sci. 2019;2(2):147-53.

23. Lar-Ndam N, Madaki J, Pitmang L, Audu M, Salihu D, Gyang M. Burnout among primary care physicians in Jos-plateau, North-central Nigeria. Niger J Fam Pract. 2015;6(2):11-8.

24. Ogundipe OA, Olagunju AT, Lasebikan VO, Coker AO. Burnout amongdoctors in residency training in a tertiary hospital. Asian J Psychiatr. 2014;10:27-32.

25. Bowling A. Mode of questionnaire administration can have serious effects on data quality. J Public Health (Oxf.). 2005;27(3):281-91.
26. Lee RT, Seo B, Hladkyj S, Lovell BL, Schwartzmann L. Correlates of physician burnout across regions and specialties: a meta-analysis. Hum Resour Health. 2013;11:48.

27. Coker AO, Adewole OA, Shoga MO, Uzodimma CC. Burnout syndrome among Orthopaedic surgeons in Lagos, Nigeria. East Cent Afr J surg. 2012; 17(2):13-7.

28. Liebenberg AR, Coetzee JF Jr, Conradie HH, Coetzee JF. Burnout among rural hospital doctors in the Western cape: comparison with previous south African studies. Afr J Prim Health Care Fam Med. 2018;10(1):e1-7.

29. Rossouw L, Seedat S, Emsley RA, Suliman S, Hagemeister D. The prevalence of burnout and depression in medical doctors working in the Cape Town metropolitan municipality community healthcare clinics and district hospitals of the provincial government of the Western cape: a crosssectional study. S Afr Fam Pract. 2013;55(6):567-73.

30. Lrago T, Asefa F, Yitbarek K. Physicians' burnout and factors in southern Ethiopia affecting it. Ethiop J Health Sci. 2018;28(5):589-98.

31. Imo UO. Burnout and psychiatric morbidity among doctors in the UK: a systematic literature review of prevalence and associated factors. BJPsych Bull. 2017;41(4):197-204

32. Panagioti M, Panagopoulou E, Bower P, Lewith G, Kontopantelis E, ChewGraham C, et al. Controlled interventions to reduce burnout in physicians: a systematic review and meta-analysis. JAMA Intern Med. 2017;177(2):195-205.

33. Upton D, Mason V, Doran B, Solowiej K, Shiralkar U, Shiralkar S. The experience of burnout across different surgical specialties in the United Kingdom: a cross-sectional survey. Surgery. 2012;151(4):493-501.

34. Martini S, Arfken CL, Churchill A, Balon R. Burnout comparison among residents in different medical specialties. Acad Psychiatry. 2004;28(3):240-2.

35. Bressi C, Porcellana M, Gambini O, Madia L, Muffatti R, Peirone A, et al. Burnout among psychiatrists in Milan: a multicenter survey. Psychiatr Serv. 2009;60(7):985-8.

36. Gabbe SG, Melville J, Mandel L, Walker E. Burnout in chairs of obstetrics and gynecology. Am J Obstet Gynecol. 2002;186(4):601-12.

37. Ozumba LN, Alabere ID. Burnout among doctors and nurses at university of Port Harcourt teaching hospital, South-South Nigeria. Arch Med Health Sci. 2019;7(1):61-8.

38. Al-Dubai SA, Rampal KG. Prevalence and associated factors of burnout among doctors in Yemen. J Occup Health. 2010;52(1):58-65.

39. Selaihem AA. Prevalence of burnout amongst physicians working in primary care in Riyadh military hospital, Saudi Arabia. Int J Med Sci Public Health. 2013;2(2):410-9.

40. Doulougeri K, Georganta K, Montgomery A, Lee A. (Reviewing Editor) "Diagnosing" burnout among healthcare professionals: Can we find consensus? Cogent Med, 2016;3:1.

41. Anduaga-Beramendi A, Beas R, Maticorena-Quevedo J, Mayta-Tristan P. Association between burnout and intention to emigrate in Peruvian healthcare workers. Saf Health Work. 2019;10(1):80-6.

42. Győrffy Z, Dweik D, Girasek E. Willingness to migrate-a potential effect of burnout? A survey of Hungarian physicians. Hum Resour Health. 2018;16:36.

\section{Publisher's Note}

Springer Nature remains neutral with regard to jurisdictional claims in published maps and institutional affiliations.

Ready to submit your research? Choose BMC and benefit from:

- fast, convenient online submission

- thorough peer review by experienced researchers in your field

- rapid publication on acceptance

- support for research data, including large and complex data types

- gold Open Access which fosters wider collaboration and increased citations

- maximum visibility for your research: over $100 \mathrm{M}$ website views per year

At BMC, research is always in progress.

Learn more biomedcentral.com/submissions 